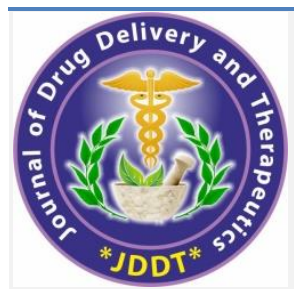

Open Access Full Text Article
Available online on 15.10.2021 at http://jddtonline.info

\section{Journal of Drug Delivery and Therapeutics}

Open Access to Pharmaceutical and Medical Research

Copyright (c) 2021 The Author(s): This is an open-access article distributed under the terms of the CC BY-NC 4.0 which permits unrestricted use, distribution, and reproduction in any medium for non-commercial use provided the original author and source are credited

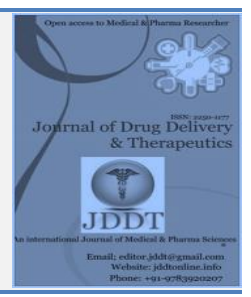

Review Article

\title{
Hazard Analysis and Critical Control Points as a Quality Risk Management Tool in the Pharmaceutical Industry: A Systematic Review
}

\author{
Meenu Chaudhary* and Priya \\ School of Pharmaceutical Sciences, Shri Guru Ram Rai University, Dehradun-248001, Uttarakhand, India
}

Article Info:

$\begin{array}{ll} & \text { Article History: } \\ & \text { Received 08 August 2021 } \\ & \text { Accepted 26 September 2021 } \\ & \text { Published 15 October 2021 }\end{array}$

\section{Cite this article as:}

Chaudhary M, Priya, Hazard Analysis and Critical Control Points as a Quality Risk Management Tool in the Pharmaceutical Industry: A Systematic Review, Journal of Drug Delivery and Therapeutics. 2021; 11(5-S):167-175

DOI: http://dx.doi.org/10.22270/jddt.v11i5-S.5094

\section{*Address for Correspondence:}

\section{Abstract}

For several years, quality risk management (QRM) has been such an integral component of healthcare as well as pharmaceutical product manufacturing. Effectual QRM can help companies make better informed and smarter choices, and furnish regulators with more prominent confirmation of an organization's capacity to manage possible dangers. In the pharmaceutical sector, the Hazard Analysis and Critical Control Points (HACCP), a QRM tool is comparatively a new approach. It is a globally perceived management system that gives rules to the pharmaceutical and food industries. HACCP approach emphasizes the hazards, with the overarching goal of ensuring that drug products are safe to use because the production of drug products is prone to health together with safety concerns. The HACCP system offers guidance to a considerable extent for quality control, by detecting, assessing, monitoring, and validating the crucial procedures and operations in the manufacturing of pharmaceutical products. The presented review article provides HACCP as a risk assessment tool, which could be applied to various parts of drug quality so that it might promote and assist the adoption of quality practices by pharmaceutical industries with the objective of improving HACCP efficiency together with company performance.

Keywords: HACCP, Hazards, QRM, Quality

Meenu Chaudhary, School of Pharmaceutical

Sciences, Shri Guru Ram Rai University, Dehradun-

248001, Uttarakhand, India

\section{INTRODUCTION}

Quality risk management has turned out to be an essential tool in healthcare organizations. Each and every manufacturing process and medicinal product have associated risks. In the pharmaceutical industry, reduction of these risks is the foundations of quality risk management as the quality of produced product have direct impact on the patient's health.

It has been more than a decade, ICH has formally introduced ICH Q9 QRM to the pharmaceutical industry. At the time of implementation of ICH Q9, the risk-based approach growingly gained prominence. Eventually, for a successful quality system the QRM was embraced being a significant element by the pharmaceutical industries. Not only in pharmaceutical companies but risk management is largely employed in other sectors as well which includes pharmacovigilance, finance, public health, insurance. For minimizing quality risks, QRM should be included in daily operations so as to develop a practice that considers quality as a key element while making any decisions. QRM makes sure and confirms that the product keeps on meeting positive risk balance which is possible through proactive determination and reduction of quality risks along with this causes of variance should be determined and selected for continuous improvement.1,2

As per ICH Q9 "Quality risk management is a systematic process for the assessment, control, communication and review of risks towards the quality of the drug (medicinal) product across the product lifecycle".

The QRM is aimed at achieving the expected quality product as well as information and risk related to it. A brief QRM procedure is represented in fig.1. 


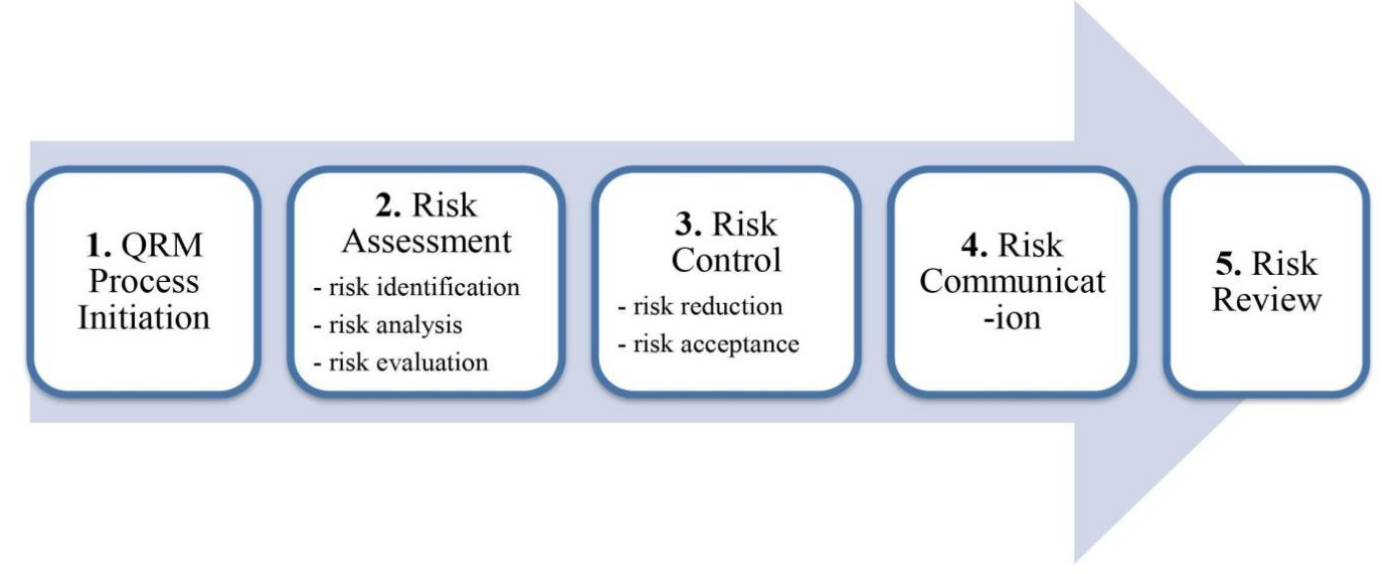

Figure 1: Brief representation of the QRM procedure.

Quality risk management procedures are comprised of the following steps. They are:

1. QRM Process Initiation: Systematic procedures that are meant to organize, simplify, as well as enhance risk-related decision-making must be included in quality risk management. For development as well as beginning of good risk management approach the mentioned steps may be utilized.

- Describe the issue or hazard question, taking into account any assumptions that may be relevant.

- Gather historical data or information relevant to the risk assessment on the potential hazard.

- For the QRM process, establish a timeframe along with an adequate quality of decision-making. ${ }^{3}$

2. Risk Assessment: The process of risk assessment includes identifying hazards, analyzing as well as evaluating the risks related to their exposure.

The basic inquiries that can be really useful are:

1. So what could possibly go wrong?

2. And what are the chances that things would go wrong?

3. Finally, What will its impacts be?

Risk identification: the process of identifying risks with the utilization of risk-related information is referred to as Risk identification. Data from the past, stakeholder concerns, and theoretical analysis are all examples of information. To the remaining approach, this step serves as the foundation

Risk analysis: The risk related to the identified hazards is estimated through risk analysis. This is a procedure that connects the probability and the seriousness of the harm. The potential for determining harm (detectability) significantly contributes to the risk estimation in certain risk management techniques or tools

Risk evaluation: Following identifying and analyzing a specific risk or hazard, risk evaluation is used to determine whether or not it falls within acceptable criteria. 4,5,6

3. Risk Control: Risk control incorporates minimization of risk or acceptance of risk by taking effective decisions. The risk control is aimed at lowering the risk enough to reach a satisfactory range. Based on the seriousness of the risk, equivalent work must be done for controlling the risk.

Risk reduction: Whenever quality risk crosses a certain limit, risk reduction emphasizes strategies for reducing or even eliminating it. Risk reduction comprises the following
- measures performed for minimizing the possibility of harm occurring

- measures performed for minimizing the possibility of the seriousness of harm

Risk acceptance: A choice of accepting risk is known as risk acceptance. Even the strongest risk management strategies may not be enough to completely remove risk for certain kinds of harm. It's really possible to affirm that a suitable strategy for risk management is executed and to a predetermined range the risk is minimized, in such cases. These predetermined ranges are determined based on a variety of factors. 7,8

4. Risk communication: exchange of risk as well as risk management details or information among decision-makers and others is referred to as risk communication. The Risk management approach outcomes have to be conveyed and recorded appropriately.

5. Review: Regarding the risk, by taking into account updated information as well as expertise, the review of risk management outcomes provides assurance that nothing changed impacting the QRM beliefs, outcomes, and findings. The quality management process examination also can identify several concerns related to the quality of the product including its safety. ${ }^{9-12}$

There are certain quality risks that can cost an organization money and even harm its reputation. Risk management is a beneficial tool in these cases. It makes an organization costeffective by identification and eradication of failure that ultimately leads to internal and external costs modes deduction. It also equips staff with resources as well as procedures to make smart choices more efficiently as it offers a viewpoint by which scientific evidence and knowledge can be seen that helps to determine alternatives and consider the possible consequences of the decision. In previous times, using flow charts, complaints, and checklists risk in the quality and operation of the product was measured. A risk management plan or strategy at present has been introduced by regulatory bodies which involve statistical and management tools including FMEA, FMECA, FTA, HACCP, HAZOP, PHA for better implementation of QRM. FMEA is the most commonly used tool of all the tools listed. However, many pharmaceutical organizations deem it as a whole QRM system in itself and rely solely on FMEA.13,14

The selection of a suitable risk assessment method is an essential step in carrying out risk analysis. Although picking up the right quality risk management tool is a crucial and difficult practice but unfortunately, the guidance related to 
the subject is minimal. The selection of the QRM tool should be such that it not only facilitate the conduction of risk management but also efficiently analyze as well as conveys information that is readily understood and also expose risks that were hidden previously.

\section{HACCP - HAZARD ANALYSIS AND CRITICAL CONTROL POINTS}

Being a tool of QRM, HACCP utilizes proactive strategy in order to identify and evaluate hazards and establish control measures aimed at prevention or eradication of hazards. Being a systematic approach, HACCP facilitates the production of reliable and safe pharmaceuticals or healthcare products by means of detection, assessment, and monitoring of safety hazards. The goal of the HACCP methodology is to prevent identified hazards to minimize risks that can arise during the pharmaceutical manufacturing process. The quality hazards are controlled to some degree by validating the critical operations as well as processes that are used in the manufacturing of the finished products as per GMP. As a result, HACCP addresses both GMP and the protection of manufacturing staff. ${ }^{15,16,17}$

HACCP's principal aim is to manufacture safe items. HACCP also has the role of reducing or in fact removing the necessity for endpoint testing which might be laborious and monotonous. Numerous organizations relied upon endpoint testing when the HACCP system was not introduced to evaluate whether the product was acceptable. Through carrying out a series of inspections throughout the process, HACCP seeks to decrease endpoint tests. In terms of prevention, all potential dangers are examined at each stage of the process and figure out what measures are adopted if there is a major hazard. HACCP aims to minimize risks to an acceptable limit as soon as the product arrives at the completion of the process. ${ }^{18,19}$

The hazards that may appear during pharmaceutical product manufacturing can be minimized to a higher degree when HACCP is employed along with some other quality tools. These risks can be either chemical, biological or physical factors that, if not prevented, are capable of causing harm. ${ }^{20}$ The right execution of HACCP empowers a company to manufacture and deliver high-quality and lower-risk products. It was also found by the experts that the inefficient execution of HACCP can result in a financial impairment.21 Thus firms essentially in the food and pharmaceutical sectors are concentrating on regular auditing as well as verification ensuring proper HACCP system execution. ${ }^{22,23}$

\section{A SHORT HISTORY OF HACCP}

- By the end of the 1950s, the HACCP methodology was established by a partnership of NASA, Natick research laboratory, and Pillsbury with the goal of ensuring that quality is integrated into the procedure throughout all stages and designing a system to evaluate food risks. ${ }^{24}$

- In 1971 during a national conference on food protection, the concept of HACCP was first got introduced to the food industry. ${ }^{25}$

- In 1985, NAS (National Academy of Science) proposed that the HACCP method be accepted by every regulatory agency for the evaluation of the efficacy of food regulation in the United States ${ }^{26}$

- The recommendation resulted in the establishment of the National Advisory Committee on Microbiological Criteria for Foods (NACMCF).
- In 1989, the NACMCF suggested HACCP's seven principles which are still used today.

- HACCP was used in the food industry but during the 1990s and 2000s, it came into existence in other sectors as well including pharmaceuticals and healthcare. ${ }^{27,28}$

\section{PRELIMINARY STEPS}

At the time of designing a HACCP strategy, 5 preliminary steps are performed initially. These steps are meant to assist in gathering background information that can aid in the execution of fundamental HACCP principles.

Form HACCP Team: It is necessary to establish a multidisciplinary HACCP team in view of the complexity and variety of possible risks with each pharmaceutical product and method. As the HACCP plan is established by the team, the team therefore ought to be made out of people who will really execute and keep up with the HACCP plan. To prevent an excessive amount of work appointed to one individual, a team having sufficient individuals or members must be established. However, there should not be too many individuals as it causes difficult communication among them. Members of the team must have detailed information and experience about the product and procedure under consideration in order to - perform hazard analysis, determine possible potential risks, determine which hazards must be observed, and suggest effective corrective action. To attain the greatest outcomes, all the team members must undergo realistic training sessions which addresses HACCP theory together with implementation 29,30

Process \& product description: Because every product has specific process steps and related hazards, a detailed overview of the process as well as product should really be created. This enables the processor to concentrate on the potential hazards associated with the form of a product. The product's description is aimed at allowing the HACCP team to become more familiar with the product in addition to the employed technology. The product's name, its condition for storage, ingredients, the process of manufacturing, packaging, and method for distribution should be incorporated in the product's description. 31

Determine the intended use: the product's final consumer or end-user should be identified, as the intended use needs to be dependent on the final consumer. The final consumer or end-user can be the general public or even a specific population segment like infants or the elderly.

Design a flow chart of the process: the flow diagram effectively and simply displays the steps involved. A chart makes it easier to understand, describe, and analyze complicated processes and related hazards. The flow chart covers the entire process, from material collection to final product shipment. But detailed process descriptions should not always be included in the flow diagram. One of the most widely adopted flow charts is the block type. ${ }^{32,33}$

Review of process flow chart: The HACCP team will evaluate the flow chart for its thoroughness once the diagram has been prepared. For ensuring that all phases are incorporated in the chart along with all other criteria, the team must gather and examine the flow chart. If needed, prior to the actual formal verification, the HACCP team can implement modifications. ${ }^{34}$

\section{HACCP PRINCIPLES}

After the preliminary tasks have been done, the next objective will be the application of HACCP principles. For 


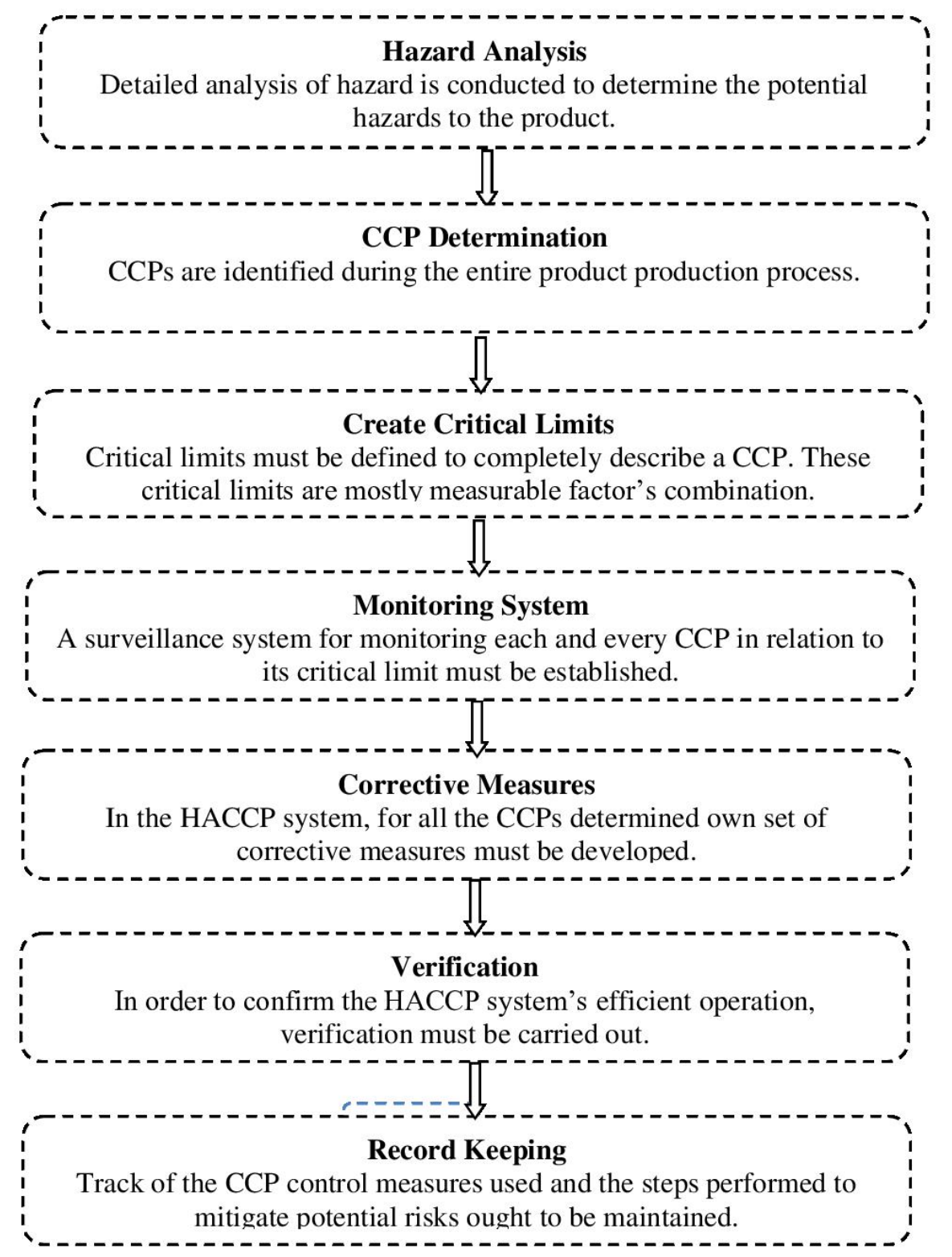

Figure 2: HACCP principles for pharmaceutical industries.

Principle 1- Hazard Analysis: being HACCP's very first principle, hazard analysis requires evaluating specific hazards in each stage of product manufacturing, testing, and distribution through the HACCP team, as soon as process flow confirmation has been established. Hazard analysis is characterized as a technique in which information in regards to hazards is gathered and assessed along with situations that contribute to the existence of these hazards, deciding the important ones that are thus covered in the HACCP plan. At the time of hazard analysis, three categories of hazards need to be evaluated: biological, chemical, and physical. ${ }^{35}$ It is recommended to carry out a two-stage risk analysis. For each and every step making a list of possible hazards could be the very first stage. The thorough risk assessment will contain-

- significant hazards as well as their possible sources

- the likelihood of a hazard occurring if no appropriate controls are in place.
- a basis for deciding whether the hazard is important enough to merit inclusion in a subsequent HACCP assessment

in the second stage, a risk assessment should be carried out which estimates the seriousness of the prospective risk and its likelihood of occurrence. ${ }^{36}$

Principle 2 - Determination of Critical Control Points (CCPs): Following the hazard analysis, the very next HACCP principle is to determine CCPs. CCP is that point where control could effectively implemented as it is considered crucial for removing and also preventing a hazard as well as bringing it within limit of acceptance. The last phase for controlling the hazard before shipment is a CCP. A CCP additionally represents a point at which loss of control results in major risk. ${ }^{37}$ The basis for the CPP creation is addressed in fig. 3 .

There could be more than just one CCP at every level where control must be implemented to manage the same risk. The 
usage of a decision tree, that promotes a logical approach, is a more efficient and suitable strategy for minimizing the number of CCP. The decision tree method inquires a series of questions concerning each processing step in which a hazard exists. These questions come in a yes/no manner, and the answers ultimately decide if that particular step is CPP or not. A control measure must be established if the hazard has been determined and its control is essential and there are no control measures. ${ }^{38,39}$

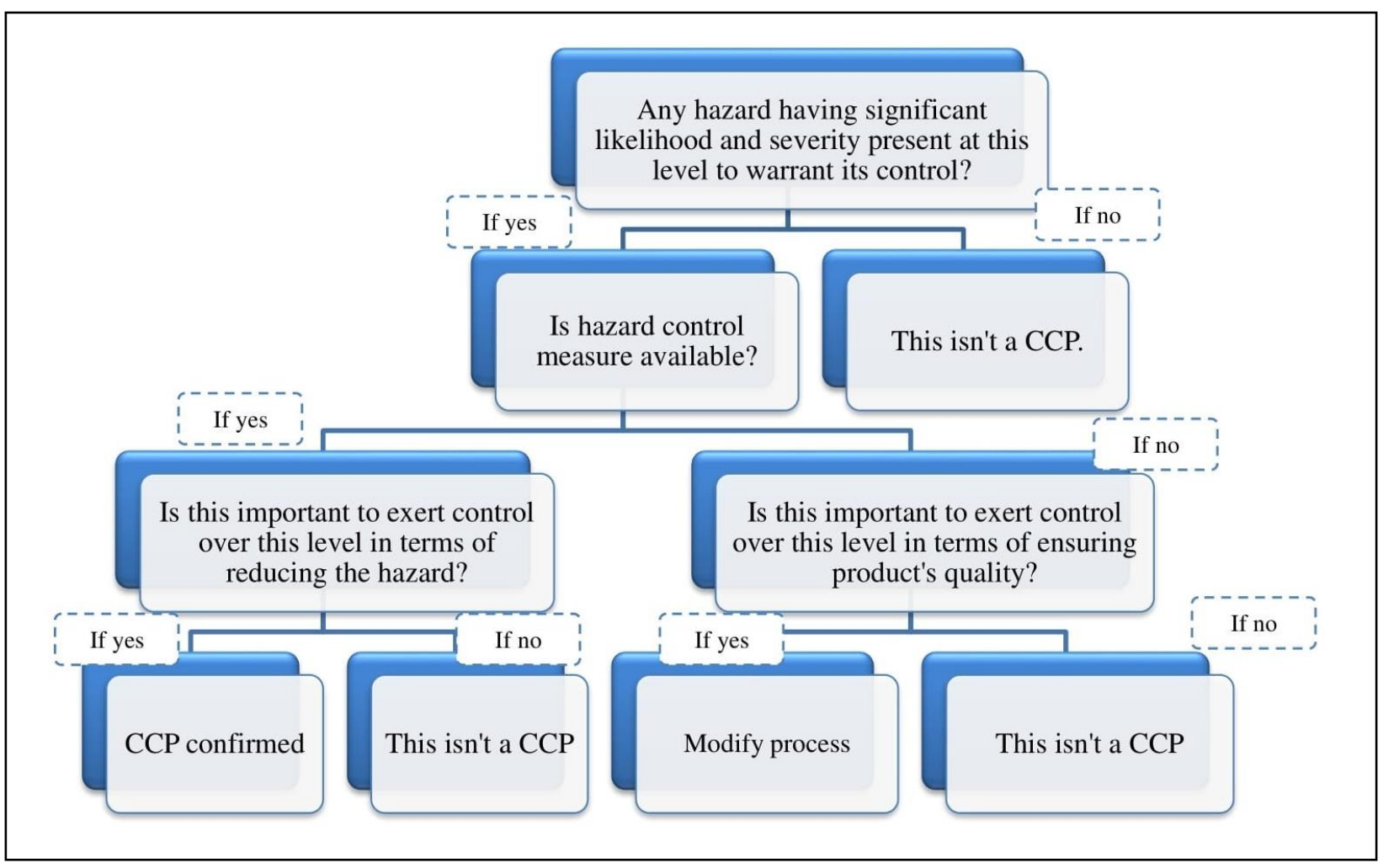

Figure 3: The basis for the CPP creation.

Principle 3 - Set Critical Limit: Critical limits must be established for every step that is a CCP after the CCPs have been determined. Critical limits are calculated using historical data or on the basis of regulatory action levels. More than a single critical limit at a specific step will be needed in certain situations. Assessments of temperature, water activity, time etc. are commonly utilized criteria. The HACCP team must be cautious in establishing critical limits which are as practicable as possible for the process in concern. Setting critical limits aids in the execution of appropriate monitoring as well as a control system. 40

Principle 4 - Develop a Monitoring System: The principle is concerned with selecting an effective technique for monitoring every CCP as well as critical limit. Monitoring every individual CCP becomes very essential since it makes sure CCPs are in conformity and avoiding exceeding the critical limitations. Control loss should be detected at the CCP by the monitoring techniques and such info should preferably be provided in good time for corrections to assure process control and avoid critical limits violation ${ }^{41}$ The critical limit is either constantly or inconstantly monitored. For measurement in periodic intervals, a computer system could really be devised. In order to make sure the system works efficiently, an individual will have to monitor or even regularly calibrate this system. In the case of the use of inconstant monitoring, industry personnel shall carry out frequent inspections. Because whenever inconstant surveillance is employed, for assuring CCP control sufficient monitoring frequency is essential. Details that are obtained through monitoring should be then examined through an authorized official who has the expertise as well as competence of taking corrective action. 42

Principle 5 - Set up Corrective Measures: no method is absolutely perfect, hence corrective action should be implemented if preventive measures fail. with the aim of addressing deviations whenever they arise, appropriate corrective measures should be established for each CCP. Creating a corrective action plan entails identifying the activities required to bring a CCP back under control in the event of a deviation, and also the plan should indicate who is accountable for taking corrective actions and to ensure that a record is kept and also retained. The supervision of corrective action should be entrusted to persons who have solid expertise in the process product and HACCP. When deviations arise in one CCP too often, there is a need to reassess the adequacy of the HACCP strategy by the HACCP team for controlling this hazard. $43,44,45$

Principle 6 - HACCP System Verification: HACCP system verification entails determining whether or not the HACCP plan is followed by the HACCP system of the facility. Verification methods shall be those apart from monitoring events which evaluate the reliability of HACCP program confirming whether or not system operates as per the design. Some processes for the verification encompass a HACCP system and its record review, deviation, and product disposition and assurance that CCPs are controlled. Despite its complexity, the successful implementation of the HACCP plan depends on the effective creation and application of the verification principle. The verification frequency needs to be sufficient to validate that the HACCP system works correctly. 
Confusion sometimes exists concerning the differences among validation and verification. Verification confirms that the HACCP plan is complied with, however, validation demonstrates that the company does what it intends to do ensuing safe product manufacturing. ${ }^{46,47}$

Principle 7 - Set up a Record keeping System: The seventh HACCP principle is to create appropriate record keeping practices. There will be no evidence that a plant does what its HACCP plan specifies without records. Records can be used to identify trends and to enhance a process over time. Documentation is essential for processes like hazard assessment, determination of the CCP, HACCP plan, as well as critical limiting. The following are some examples of activities where the records are needed: critical limits; process steps; deviations; modifications to the HACCP system. ${ }^{48,49}$

\section{BARRIERS OR CHALLENGES TO SUCCESSFUL IMPLEMENTATION OF HACCP}

Regardless of the huge appreciation of HACCP systems, It has been noted that HACCP systems were not adopted entirely in the pharma field. The presence of barriers is an explanation behind not adopting the system as it can impede the utilization of the system. HACCP framework won't be executed all over the pharmaceutical field and also it won't arrive at its maximum potential till the barriers are removed. All the activities, behaviors as well as beliefs that have a negative impact on the HACCP concept's understanding along with the application and retention of the HACCP principle are referred to as barriers. Some of the barriers have been discussed here. $50,51,52$

1. The HACCP implementation might be problematic for pharmaceutical enterprises, which are small to mediumsized, owing to the unavailability of sufficient resources, practical expertise, and skilled staff for execution of HACCP, while it may be easier to do so for relatively large companies. ${ }^{53,54}$

2. Lack of motivation and monitoring- employee motivation plays a key role in keeping the HACCP system functioning. For proper operation of HACCP, at all stages staff supervision is essential. the motivated staff of the HACCP system performs a major role in the application and keeping up with the HACCP framework, in particular with regard to the requirements for constant surveillance and reporting 55

3. The unavailability of staff with HACCP knowledge and understanding is seen as one of the major barriers which arise due to the absence of training for employees. Normally, training courses are specifically tailored for staff or groups according to their technical knowledge level and responsibility in the entire process of HACCP. And thus this enables personnel to utilize the HACCP concept in their specific processes. ${ }^{56,57}$

4. the implementation cost of HACCP is quite expensive in small pharmaceutical companies, its low purchasing capacity is usually unable to support it and furthermore can't convince or push its suppliers sufficiently to begin utilizing the HACCP system. 58

\section{ADVANTAGES OF HACCP IMPLEMENTATION IN THE PHARMACEUTICAL INDUSTRY}

HACCP has no limitations on its advantages. Owing to its applicability and compatibility, HACCP can be deployed almost anywhere in the world. The main advantages of implementation of HACCP are:
- The merits of the application of HACCP comprise improving resource use and fast solutions to safety problems of products in addition to increasing the safety of the medicinal products.

- The HACCP plan is tailored specifically for a given product and operating method. Technological advancement or Modifications in operating techniques can be accommodated by the HACCP system.

- Consumers are the primary beneficiaries since the system promises safety products and results in the manufacture of quality items.

- HACCP leads to a decrease in the quantity of required end product's laboratory testing, decrease in the noncompliant product count, even for controlling process there is a decrease in required sampling plans

- As a result of improved awareness as well as training operational errors by humans might become less prevalent.

- Using a HACCP framework allows for enhanced process control, increased employee devotion, and lower failures.

- Faith and confidence of consumer's increases and the likelihood of product recall are minimized thus lowering the costs of the product.

- HACCP can assist regulatory agencies in conducting inspections, mostly due to documentation and recordkeeping, and by enhancing belief in the safety of drugs it encourages international trade and also encourages company stability.

- HACCP Improves quality system efficacy through emphasizing critical parts that a procedure has and also on preventing issues instead of depending upon finished product testing. ${ }^{59-62}$

There are numerous examples of HACCP implementation. Few case studies have been published with regard to HACCP use in the pharmaceutical sector. A selection of those is accessible here, which may aid the reader in conducting a more comprehensive assessment of the literature. These might be a useful reference we believe, for others including labs and that could promote their decision to build a systematic process of risk analysis including the use of HACCP-based systems of safety, particularly in pharmaceutical industries.

As such, these inclusions are not meant to codify the findings emerging from individual conclusions from a quality standpoint. Instead, inclusion in this section shows that the case represents a recognized area of quality interest as well as a practical and effective case of risk management used for efficient analysis, issue solving, and management of decisions. A review of such type is used to incorporate historical research and can allow present as well as future professionals and researchers to create their methodological decision for upgrading the sector by using appropriate guidelines or techniques.

Glory Bansal et al.63 in the paper exhibits the use of the HACCP approach to immunosuppressant drug manufacturing by identifying CCPs and suggesting control measures and corrective actions for process management. The authors have also shown that how the approach contributed to concentrating on production phases, which can have a major impact on the quality of the product and have improved processes and used CCPs and CCP decision tree in identifying the CCP to set risk management priorities 
Tim Sandle 64 in the author's study, HACCP as a risk assessment tool was employed to highlight how in good manufacturing controls, risk assessment may be included The case studies feature the transfer of a series of sterilizing stoppers in a sterile production facility to a filling machine from an autoclave. Many risk variables have to be taken into account for the analysis of aseptic processing and thus the HACCP technique can aid in identifying these risks.

Carducci Annalaura et al. 65 the Author illustrates how HACCP may be utilized to formally, and clearly control bacterial endotoxins testing as well as other analytical procedures, leading to improved and even more consistent analytical results, considering the various errors that may impact BET (Methodology, equipment, reagents, etc.). It also illustrated how Haccp helps standardize every process phase

Tim Sandle 66 discusses a case study on how a viral risk from a pharmaceutical process might be eliminated via HACCP. The paper addresses the relevance of process controls and the focus on controls by means of risk evaluation. significantly, viral security can only be achieved with a combination of measures. The author emphasized modern approaches and strategies in the paper.

Ziegler et al. 67 has applied the quality risk management principles in this case study for the analysis of monitoring frequencies and sample sites in the hormonal tableting unit. The author also showed how a general risk assessment method centered upon the HACCP method for assessing the premises (namely production areas as well as clean areas) was established with a view to microbial load and to assessing whether the available monitoring program was meeting improved environmental monitoring practices or not. Since environmental surveillance is of major relevance in industries having a high microbial contamination sensitivity, for instance, parenteral plants or biotechnological plants.

Brigitte bonan et al., 68 the Author outlines the implementation of HACCP method for anti-cancer drug production, In order to identify important control points and to provide control measures for managing the cancer chemotherapy process. The author also describes how a multidisciplinary team was constituted in accordance with HACCP to define and evaluate the cancer chemotherapy procedure. All the critical points were enumerated by the team \& based on their occurrence rate, severity, and detectability their risk indexes were determined. and for every risk that has been identified the team developed monitoring, controlling, and corrective measures.

Tim sandle 69 The author has used risk evaluations and risk filtering techniques based on HACCP for showing how to build a framework in biotechnological production for environmental monitoring frequencies and demonstrates the appropriateness of the framework in a case study.

Linda Bissett ${ }^{70}$ In order to ensure that every step performed during any process of decontamination reduces the risk of healthcare-associated infections (HCAIs), the author described the ways in which HACCP can be implemented, assuring that uniform standard are based upon guidelines.

\section{CONCLUSION}

Although pharmaceutical products have made significant improvements to enhance their quality, there are still many challenges that need consideration in this field. Quality Risk Management gives confirmation that the dangers are satisfactorily overseen and furthermore helps in settling on consistent and traceable choices to drug industry that will decrease the danger through steady utilization of tools and periodic review. Risk management is a systematic procedure that incorporates risk - identification, analysis, assessment, and the development of risk management strategies. It uses various tools that are widely accepted in pharmaceuticals but It has been discovered that there is an over-dependence on retrospective approaches, that deal with the issues after they've happened instead of preventing issues in the first place. As a prospective tool, HACCP in the pharmaceutical sector is the best-suited method for risk management because the emphasis is not primarily on end-product testing, but on preventing dangers leading to a reduction in product recall with various other quality issues. The HACCP approach profits everyone, including consumers and pharmaceutical companies, because it is cost-effective, resulting in less product loss and also ensuring the pharmaceutical product's safety. As a result, it is suggested that tools like HACCP must be employed in pharmaceutical companies to prevent losses and product rejections owing to poor quality in order to achieve the purpose of business.

\section{ACKNOWLEDGEMENT}

The authors would like to extend their sincere thanks to School of Pharmaceutical Sciences, Shri Guru Ram Rai University, Dehradun, India, for their essential guidance over the duration of the study.

Relevant conflicts of interest/financial disclosures: The authors declare that the work was conducted in the absence of any commercial or financial relationships that could be construed as a potential conflict of interest

\section{REFERENCES}

1. Sivadasu S, Gangadharappa HV, Quality risk management: a review, International Journal of Pharmaceutical Sciences Review and Research, 2017; 44(1):142-148

2. Reddy VV, Quality risk management in pharmaceutical industry:a review, International Journal of Pharmtech Research, 2014; 6(3):908-914

3. Lotlikar MV, Quality risk management (qrm): a review, Journal of Drug Delivery \& Therapeutics, 2013; 3(2):149-154 https://doi.org/10.22270/jddt.v3i2.447

4. Pharmaceutical CGMPS for the 21st century - A risk-based approach, FDA, 2004

5. Pharmaceutical quality system, ICH Harmonized Tripartite GuidelineQ10, 2008

6. Development and Manufacture of Drug Substances (Chemical Entities and Biotechnological/Biological Entities). Draft Consensus Guideline Q11, 2011

7. Risk Management: Guidelines and Best Practices Missouri Information Technology Advisory Board Project Management Committee Risk Management Subcommittee, 2003.

8. Risk Management - Vocabulary - Guidelines for Use in Standards, International organization for Standardization, 2002

9. Nauman M, Bano R, Implementation of quality risk management (qrm) in pharmaceutical manufacturing industry, IOSR Journal of Pharmacy and Biological Sciences, 2014; 9(1):95-101 https://doi.org/10.9790/3008-091495101

10. Shelar SS, Quality risk management (qrm) in pharmaceutical industry: tools and methodology, International Journal of Innovative Research In Technology, 2020; 7(1):811-816

11. WHO Guideline On Quality Risk Management Working document QAS/10.376/Rev.2 August 2012

12. Guidance for Industry: Quality Risk Management Version 1.0 Drug Office Department of Health Guidance. Available at: 
https://www.drugoffice.gov.hk/eps/do/en/doc/guidelines_for ms/Guidance\%20for\%20industry_QRM_201312.pdf

13. Venkatesh MP, Nagendra SR, Pramod KTM, Opportunities and challenges in the implementation of ICH Q9 with emphasis to a WHO approved pharmaceutical plant, International Journal of Research in Pharmacy and Science, 2017; 7(2):15-22

14. Sharma A, Jeyaprakash MR, Bora R, Chandra A, Impact of quality risk management process in pharmaceutical industry to curtail the non-conformity, International Journal of Pharmaceutical Quality Assurance, 2020; 11(1):179-185. https://doi.org/10.25258/ijpqa.11.1.28

15. WHO Technical Report Series No 908, 2003 Annex.7

16. World Health Organization, Quality Assurance of Pharmaceuticals, A Compendium of Guidelines and Related Materials, Volume 2. Geneva, 2004.

17. Jain, S. Quality by design (QBD): a comprehensive understanding of implementation and challenges in pharmaceuticals development", International Journal of Pharmacy and Pharmaceutical Sciences, 2014; 6(1):29-35.

18. Bauman, H, HACCP: Concept, development, and application, Food Technology, 1990; 44(5):156-158.

19. Mortimore, S. and Wallace, C. HACCP: A Practical Approach, 2" Ed. Aspen Publishers, Gaithersburg, MD. 2000

20. Wagh DG, Shahi SR, Magar DR, Ingle TB, Khadbadi SS, Gugulkar $\mathrm{R}$, Karva GS, Quality by design in product development: A review, Indo Journal of Pharmaceutical Research, 2015; 5:166780

21. O'Neill, Peter, Sohal, Amrik, Teng, Wei C,Quality management approaches and their impact on firms ' financial performanceAn Australian study, International Journal of Production Economics, 2016; 171: 381-393. https://doi.org/10.1016/j.ijpe.2015.07.015

22. Cormier RJ, Mallet M, Chiasson S, Magnu'sson H, Valdimarsson G Effectiveness and performance of HACCP-based programs, Food Control, 2007; 18(6): 665-671. https://doi.org/10.1016/j.foodcont.2006.02.019

23. Wallace CA, Holyoak L, Powell SC, Dykes FC, Re-thinking the HACCP team: An investigation into HACCP team knowledge and decision-making for successful HACCP development, Food Research International, 2012; 47(2):236-245. https://doi.org/10.1016/j.foodres.2011.06.033

24. Ross-Nazzal, J, From Farm To Fork: How Space Food Standards Impacted The Food Industry And Changed Food Safety Standards. In S. J. Dick and R. D. Launius (Eds.) Societal Impact of Spaceflight, Washington, DC: NASA, 2007; 219-236

25. Sandrou K, Arvanitoyannis S, Application of hazard analysis critical control point (haccp) system to the cheese-making industry: a review, Food Reviews International, 2000; 16(3):327-368 https://doi.org/10.1081/FRI-100100291

26. National Research Council (US) Subcommittee on Microbiological Criteria. An Evaluation of the Role of Microbiological Criteria for Foods and Food Ingredients, Washington (DC): National Academies Press (US), 1985

27. Anon. Recommendations of the US National Advisory Committee on Microbiological Criteria for Foods: I HACCP principles, II meat and poultry, III seafood, Food Control, 1991; 2(4):202-211 https://doi.org/10.1016/0956-7135(91)90188-3

28. Woodcock J, The concept of pharmaceutical quality. American Pharmaceutical Review, 2004, 7(60):10-15

29. Mayes T, HACCP training. Food Control, 1994; 5(3):190-5. https://doi.org/10.1016/0956-7135(94)90082-5

30. Mortimore S, Wallace C, HACCP: A Practical Approach, 2"Ed. Aspen Publishers, Gaithersburg, MD, 2000.

31. Ababouch, $\mathrm{L}$, The role of government agencies in assessing HACCP. Food Control, 2000; 21(2):137-142. https://doi.org/10.1016/S0956-7135(99)00071-7
32. Cusato $S$, Tavolaro $P$, Oliveira CAF, Implementation of Hazard Analysis and Critical Control Points System in the Food Industry:Impact on Safety and the Environment, 2019

33. Umi R, Norazmir, M.N. A systematic review on hazard analysis and critical control points (haccp) in southeast asia countries, Indian Journal of Public Health Research \& Development, 2021 12(2):420-425

34. Quinn BP, Marriott NG, HACCP plan development and assessment: a review, Journal of Muscle Foods , 2002 13(4):313-330 https://doi.org/10.1111/j.17454573.2002.tb00339.x

35. Tompkin, RB, HACCP in the meat and poultry industry. Food Control 1994. https://doi.org/10.1016/0956-7135(94)90075-2

36. Mayes T, How can the principles of validation and verification be applied to hazard analysis? , Food Control, 1999, 10(4/5), 277 279. https://doi.org/10.1016/S0956-7135(99)00018-3

37. Weddig, LM, HACCP: A Systematic Approach to Food Safety, 3' Ed., The Food Processors Institute, Washington, D.C. 1999, pp. 81-84

38. NACMCF. Hazard analysis and critical control point principles and application guidelines. Journal of Food Protection. 1998; 61:762-775.

39. Sandle T, Mattia MD, Leavy C, Use of Hazard Analysis Critical Control Point (HACCP) methodology for biocontamination control: Assessing microbial risks and to determining environmental monitoring locations, European Journal of Biomedical and Pharmaceutical Sciences, 2019; 243:18-45 https://doi.org/10.37521/ejpps.24302

40. King, P, Implementing a HACCP program, Food Management, 1992; 27(12):54,56,58

41. Sohrab, Risk assessment a pre-requisite for application of HACCP in food industries, Indian Food Packer, 1999; 53(4):43 50

42. Tompkin, RB, In HACCP in Meat, Poultry and Fish Processing Advances in meat research series, Blackie Academic \& Professional, London, 1995: 72-108 https://doi.org/10.1007/978-1-4615-2149-5_5

43. Snyder, OP, HACCP in the retail food industry, Dairy, Food and Environmental Sanitation, 1991; 11(2):73-81.

44. Kvenberg J, Stolfa P, Stringfellow D, Garrett ES, HACCP development and regulatory assessment in the United States of America. Food Control, 2000; 11:387-401. https://doi.org/10.1016/S0956-7135(99)00090-0

45. Sperber WH, The modern HACCP system, Food Technology, 1991; 45(6):116, 118, 120.

46. Lupin HM, Internal auditing of HACCP-based systems in the fishery industry, INFOFISH International, 2000; 4:56-64.

47. Sperber WH, The role of validation in HACCP plans, Dairy, Food and Environmental Sanitation, 1999; 19(12): 912-920.

48. Dahiya S, Khar RK, Chhikara A, Opportunities, challenges and benefits of using haccp as a quality risk management tool in the pharmaceutical industry, Quality Assurance Journal, 2009; 12(2):95-104 DOI: 10.1002/qaj.446 https://doi.org/10.1002/qaj.446

49. Patil R, Gangadharappa HV, Kiran HC, Sandhya K, Planning of Hazard Analysis Critical Control Point (HACCP) in Pharmaceuticals, International Journal of Pharmaceutical Sciences Review and Research, 2016; 37(1):149-154

50. Bas M, Ersun SA and Kivanc G, Implementation of HACCP and prerequisite programs in food businesses in Turkey, Food Control, 2006; 17:118-126. https://doi.org/10.1016/j.foodcont.2004.09.010

51. Taylor E, HACCP in small companies: benefit or burdens, Journal of Food Control, 2001; 12: 217-222 https://doi.org/10.1016/S0956-7135(00)00043-8 
52. Panisello PJ, Quantick PC, Technical barriers to hazard analysis critical control point, Food Control, 2001; 12(3):165-173. https://doi.org/10.1016/S0956-7135(00)00035-9

53. Mortlock MP, Peters AC, Griffith CJ, Food hygiene and hazard analysis critical control point in the United kingdom food industry: practices, perceptions and attitudes, Journal of Food Protection, 1999; 62(7):786-792. https://doi.org/10.4315/0362-028X-62.7.786

54. Panisello PJ, Quantick PC, Knowles MJ, Towards the implementation of HACCP: results of a Uk regional survey, Food Control, 1999; 10(2):87-90. https://doi.org/10.1016/S09567135(98)00161-3

55. Giampaoli J, Sneed J, Cluskey M and Koenig HF, School foodservice directors' attitudes and perceived challenges to implementing food safety and HACCP programs, The Journal of Child Nutrition \& Management, 2002; 26(2)

56. Youn S, Sneed J, Training and perceived barriers to implementing food safety practices in school food service, The Journal of Child Nutrition \& Management, 2002; 26(1).

57. Yadav H, Mahna R, Rekhi TK, HACCP system and difficulties in its implementation in food sector paripex, Indian Journal of Research, 2015; 4(7):306-309

58. Maldonado ES, Henson SJ, Caswell JA, Leos LA, Martinez PA, Aranda G, Cadena JA, Cost-benefit analysis of HACCP implementation in the Mexican meat industry, Food Control, 2005; 16:375-381.

https://doi.org/10.1016/j.foodcont.2004.03.017

59. Singh D, Kumar A, Singh A, HACCP In Clean Food Production: An Overview, International Journal of Research, 2018; 6(12):128134 https://doi.org/10.29121/granthaalayah.v6.i12.2018.1096

60. Bauman HE. The origin and concept of HACCP. In: Pearson AM, Dutson TR, editors. HACCP in meat, poultry and fish processing. London: Chapman \& Hall; 1995.P. 1-7. https://doi.org/10.1007/978-1-4615-2149-5_1

61. McAloon TR. HACCP implementation in the United States. In: Mayes T, Mortimore S, editors. Making the most of HACCP: learning from others' experience. England: Woodhead; 2003. P. 61-80. https://doi.org/10.1533/9781855736511.2.61

62. Ehiri JE, Morris GP, McEwen J, Implementation of HACCP in food businesses: the way ahead, Food Control, 1995; 6(6):341-5 https://doi.org/10.1016/0956-7135(95)00045-3

63. Bansal G, Parashar B, Dhamija H, The Application of haccp and Risk Management in the Pharmaceutical Process, Asian journal of pharmaceutical and clinical research, 2013; 6(2):21-25

64. Sandle T, Aseptic transfer risk assessment: a case study, Journal of Validation Technology, 2015; 21(1):1-10

65. Annalaura, C, Giulia D, Stefano C, The application of quality risk management to the bacterial endotoxins test: use of hazard analysis and critical control points, PDA Journal of Pharmaceutical Science and Technology, 2013; 67(5):553-67 https://doi.org/10.5731/pdajpst.2013.00938

66. Sandle T, Current methods and approaches for viral clearance, American Pharmaceutical Review, 2015; 18:1-4.

67. Ziegler I, Borbély-Jakab J, Sugó L, Kovács RJ, Revision of viable environmental monitoring in a development pilot plant based on quality risk assessment: a case study, PDA Journal of Pharmaceutical Science and Technology, 2017; 71(3):234-244 https://doi.org/10.5731/pdajpst.2016.007096

68. Bonan B, Martelli N, Berhoune M, Maestroni ML, Havard L, Prognon $\mathrm{P}$, The application of hazard analysis and critical control points and risk management in the preparation of anticancer drugs, International Journal for Quality in Health Care 2009; 21(1), 44-50 https://doi.org/10.1093/intqhc/mzn052

69. Sandle T, Application of quality risk management to set viable environmental monitoring frequencies in biotechnology processing and support areas, PDA Journal of Pharmaceutical Science and Technology, 2012; 66(6):560-579 https://doi.org/10.5731/pdajpst.2012.00891

70. Bissett L, Developing decontamination strategies and monitoring tools, British Journal of Nursing, 2010; 19(16):12-17 https://doi.org/10.12968/bjon.2010.19.Sup6.78212 